\title{
INCIDENCE OF OCULAR AND SYSTEMIC ASSOCIATIONS WITH CONGENITAL PTOSIS, ITS MANAGEMENT AND COMPLICATIONS FOLLOWING PTOSIS SURGERY
}

\author{
Thenmozhi Sethuraja R1, Radhakrishnan $M^{2}$
}

${ }^{1}$ Senior Assistant Professor, Department of Ophthalmology - Oculoplasty, Government Mohan Kumaramangalam Medical College Hospital, Salem.

${ }_{2}^{2}$ Retired Director, Department of Ophthalmology - Oculoplasty, Regional Institute of Ophthalmology, Government Ophthalmic Hospital, Chennai.

\section{ABSTRACT}

\section{$\overline{\text { AIM }}$}

To analyse the various ocular and systemic associations of congenital ptosis and study the effect of associated anomalies on the management of ptosis, visual acuity and complications following surgery.

\section{DESIGN}

Prospective and interventional study.

\section{PARTICIPANTS}

One hundred and forty six congenital ptosis patients were taken up for this prospective and interventional study.

\section{METHODS}

These patients were completely examined for ocular and systemic anomalies with proper preoperative evaluation. Documentations were made with pre- and post-operative photographs and the results were analysed.

\section{RESULTS}

Among one hundred and forty six patients, 87 (59.6\%) had severe ptosis, 21 (14.4\%) patients reported with moderate ptosis and $38(26 \%)$ had mild ptosis; 77 (52.7\%) patients with simple congenital ptosis formed major group, 30 (20.5\%) reported with superior rectus muscle weakness, 13 (8.9\%) had Marcus Gunn jaw-winking phenomenon and 11 (7.5\%) had Blepharophimosis syndrome among ocular association. Frontalis sling surgery performed in 70(47.9\%) patients formed the major group among congenital ptosis surgery. Out of 124 patients who underwent surgery, 6 patients had recurrent ptosis due to slipping of knot and under correction was found in 11 patients.

\section{CONCLUSION}

Severe congenital ptosis was found in 87 (59.6\%) patients and 77 (52.7\%) simple congenital ptosis formed the major group. Superior rectus weakness formed the major component of ocular association and congenital heart disease was common among systemic association. Regarding congenital ptosis surgery, frontalis sling played a major role with good results and minimal complication.

\section{KEYWORDS}

Congenital Ptosis, Marcus Gunn Jaw-Winking Phenomenon, Blepharophimosis Syndrome, Oculocerebral Auriculo Dental Anomalies, Noonan's Syndrome, Arthrogryposis Multiplex.

HOW TO CITE THIS ARTICLE: Thenmozhi Sethuraja R, Radhakrishnan M. Incidence of ocular and systemic associations with congenital ptosis, its management and complications following ptosis surgery. J Evolution Med Dent Sci 2016;5(6):309-313,

DOI: $10.14260 /$ jemds/2016/67

\section{INTRODUCTION}

Ptosis, "Blepharoptosis" (From Greek, to fall) is a drooping or falling of the upper eyelid. Congenital ptosis is commonly caused by a developmental dystrophy of the levator muscle, which elevates the upper eyelid and is present since birth. It is of unknown etiology with strong hereditary tendency. ${ }^{1}$ When levator receives maximum innervations during opening, the orbicularis receives minimum innervations and vice versa.

Frontalis partly contribute to lid elevation above the line of vision in extreme upgaze and also it compensates the levator action in levator dystrophy. ${ }^{2}$

Financial or Other, Competing Interest: None.

Submission 20-11-2015, Peer Review 21-11-2015,

Acceptance 14-12-2015, Published 20-01-2016.

Corresponding Author:

Thenmozhi Sethuraja R,

FO-6, IV Floor, Vaibhav Apartments,

Natesan Colony, Shankar Nagar, Salem-7.

E-mail: sairagav44@gmail.com

DOI:10.14260/jemds/2016/67
Deficiency of striated muscle fibres, which causes inability of muscle to contract and relax so that elevation of lid to its normal level in primary gaze and relaxation restriction results in lid lag on looking down. ${ }^{2}$

\section{MATERIALS AND METHODS}

Study population: 146 patients

Study period: $\quad$ 2007-2009

Study place: Oculoplasty Department of Regional Institute of Ophthalmology and Government

Ophthalmic Hospital, Chennai.

Study type: $\quad$ Prospective and interventional study.

Study tool: History and clinical examination.

\section{Patient Demographics and Preoperative Evaluation}

In this prospective study, 146 patients with congenital ptosis were analysed in Oculoplasty Department of Regional Institute of Ophthalmology and Government Ophthalmic Hospital, Chennai, over a period of two years. Congenital ptosis of all grades with or without ocular and systemic associations were included in this study. Post-traumatic, post-surgical, 
mechanical, post-inflammatory and pseudoptosis were excluded from this study.

A detailed history including birth, family, onset associated syndromes with proper examination of patient was done as per the pneumonic mentioned below.

\section{$\mathrm{AB}^{2} \mathrm{CD}^{2} \mathrm{E}$ and DESTINY}

A- Amount of levator function - ILIFF TEST.

B- Berke's method of measuring levator action, Bell's phenomenon.

C- Corneal sensation.

D- Droop (degree of ptosis), Dryness-Schirmer test.

E-Extraocular movements - Superior rectus action. ${ }^{3}$

Along with this, margin reflex distance 1 and 2, yawn for Marcus Gunn jaw-winking phenomenon were examined. Surgical procedures were planned according to levator action, Bell's phenomenon and amount of ptosis. ${ }^{4}$ Iliff's test was done for younger children and Berke's method for older children for the measuring amount of levator action. ${ }^{5}$

\begin{tabular}{|c|c|}
\hline \multicolumn{2}{|c|}{ BERKE'S METHOD } \\
\hline AMOUNT OF PTOSIS & LEVATOR ACTION \\
$<2 \mathrm{~mm}$ - Mild & $15 \mathrm{~mm}$ - normal \\
$2-4 \mathrm{~mm}$ - Moderate & $>8 \mathrm{~mm}$ - Good \\
$4 \mathrm{~mm}$ - Severe & $5-7 \mathrm{~mm}$ - Fair \\
& $<4 \mathrm{~mm}$ - Poor \\
\hline
\end{tabular}

Seventy patients with severe ptosis ( $4 \mathrm{~mm}$ or more) and poor levator action ( $3 \mathrm{~mm}$ or less) were treated with fox pentagon frontalis sling surgery. Levator resection was done in 21 patients with moderate ptosis and good levator function (5$7 \mathrm{~mm}$ ) through transcutaneous approach (Anterior) and Fasanella Servat procedure was done in three patients with mild ptosis. Post operatively, patients were reviewed on the first and fifth day, and advised monthly followup for 6 months period. Surgical outcomes were analysed and complications were noted. Six patients with recurrent ptosis due to slipping of knot in sling surgery underwent re-surgery after 3 months. Under-correction was noted in 11 patients.

\section{RESULTS}

Among 146 congenital ptosis, patients aged ranging from 1 year to 30 years were included in this study. Most of them were reported for cosmetic purpose (93\%) and 7\% for defective vision. Degree of ptosis noted were classified in to severe in 87 patients (59.6\%), moderate in 21 (14.4\%)- (Photo no-1) and mild in 38 patients (20.5\%).Majority of the congenital ptosis reported were simple type (52.7\%), common ocular association found was superior rectus palsy (20.5\%), Marcus Gunn jaw winking phenomenon $(8.9 \%)$ and $7.5 \%$ patients had Blepharophimosis syndrome. Ocular associations with congenital ptosis were listed in: (Table -1).

Thirteen patients had associated systemic anomalies, out of which congenital heart disease and delayed mile stones formed a major group. Incidence of systemic associations were showed in pie diagram.

One hundred and twenty four patients underwent surgeries for congenital ptosis, among these, Frontalis sling played a major role $(47.9 \%)$. Levator resection was planned for 21 patients $(14.4 \%)$ in moderate and mild ptosis according to Geoffrey J Gladstone and Sydney Fox ptosis surgery based on marginal limbal distance formula.6,7

\section{AMOUNT OF RESECTION}

Bilateral ptosis $\rightarrow 9-$ MLD of ptotic eyelid x3

Unilateral ptosis $\rightarrow$ MLD of normal eyelid -MLD of ptotic eyelid $\times 3$
Levator disinsertion with frontalis sling surgery were done in 13 patients with Marcus Gunn jaw-winking phenomenon $(8.9 \%)$. Along with frontalis sling, double Z plasty also done in 11 patients with Blepharophimosis syndrome (7.5\%). Squint surgery followed by sling surgery were done in 4 exodeviated and 2 esodeviated patients. ${ }^{8}$ Crutch glasses were given to 2 patients with chronic progressive external ophthalmoplegia. ${ }^{9}$ frontalis sling was not done due to absence of Bell's phenomenon. Outcomes of different types of surgery were in (Table 2).

Under-correction formed the major complication reported in this study. It was noticed in 11 patients (7.5\%); 6 patients reported with recurrent ptosis due to slipping of knot, for which re surgery was done after 3-6 months.

Out of the cases included in this study, 121 had $6 / 6$ vision, 27 cases had $6 / 12$, but corrected to $6 / 6$ with spectacles and 6 reported with amblyopia of 6/60 NIP vision.

\section{DISCUSSION}

Out of this, one year to 20 years formed major group of 128 cases with $82.5 \%$, more than $50 \%$ of the patients belong to the age group of 5-15 years. This may be due to cosmetic awareness. Ocular and systemic associations were noted in 81 patients. Unilateral ptosis was more common with ipsilateral superior rectus palsy. 10

Simple congenital ptosis formed major group, this correlates with beard series (75\%), Yanoff study (69\%) and Spaeth (76\%). Marcus Gunn jaw winking phenomenon (Photo no-2) noted in 13 patients (8.9\%) which was lower than in Beard study. Familial incidence were noted in Blepharophimosis syndrome in $7.5 \%$ which was higher than Nelson study (6.9\%). Primary ovarian failure in FOX $\mathrm{L}_{2}$ mutation was reported in several studies, but no such history of menstrual irregularity and primary infertility were noted among adult female Blepharophimosis (photo-3) patients.11,12 Six cases had strabismus (4.1\%), of which 4 were associated with exodeviation, 2 had esodeviation. Three patients had nystagmus, 2 each had Duane's syndrome, congenital coloboma of choroid and iris and CPEO with $1.4 \%$ and 1 case of congenital myasthenia gravis. In this study, 6 cases were found with amblyopia due to anisometropia and occlusion. Amblyopia in congenital ptosis was noted in $6.9 \%$ in case of Nelson study and Drayer et al. study.

Out of 146 cases, 12 cases of systemic associations were noted. Four had congenital heart disease, out of that atrial septal defect formed the major group with $2.7 \%$. Two cases of Noonan's syndrome consisting of congenital ptosis, cataract, atrial septal defect, patent ductus arteriosus, webbed neck, low set ears with short stature and pectus excavatum was reported. Noonan's syndrome was named after Dr. Jacqueline Noonan. One child reported with congenital ptosis, cleft lip, cleft palate and bifid uvula $(0.7 \%){ }^{13}$ Two cases of arthrogryposis multiplex congenita was reported with mild ptosis in the left eye.

It was associated with genu valgum, occurred usually in maternal myasthenia gravis. One case $(0.64 \%)$ came with congenital Blepharophimosis syndrome, telecanthus, cerebral palsy, mental retardation, dental malformations, bat ears, convergent squint with developmental delay and came to diagnosed as a syndrome of oculo-cerebro-dento-auricular malformations (CODAS) syndrome a rare autosomal recessive syndrome with $<1 / 1000000$ incidence. ${ }^{5}$ Surgery was deferred due to protein energy malnutrition and low weight. 14 Four cases of delayed milestones were reported with congenital ptosis. Out of the cases included in this study 121 had 6/6 vision, 27 cases had $6 / 12$, but corrected to $6 / 6$ with spectacles and 7 reported with amblyopia of $6 / 60$ NIP vision.

Out of 146 cases, 124 underwent surgery (84.9\%), 45 cases were done under general anaesthesia; 79 cases were 
done under local anaesthesia. Local anaesthesia gave better assessment of lid level per operatively compared with other eye. Fasanella-servat was done in 2 cases of male and 1 female, who had mild ptosis with good levator function. The main complication occurred in this surgery was central peaking. This was prevented by proper placement of haemostasis; 41 males and 29 females of 70 cases underwent frontalis sling surgery.

It was done with fox pentagon technique that gave good results.6,15 In recent advances, non-absorbable sutures such as silicone rods and Mersilene mesh were used in ptosis surgery. But in this study, 4-0 Prolene was used as suspensory material with good results. Even though bilateral sling produce a symmetrical result on down gaze for cosmetic similarities, in this study only the affected eye was operated since the patients were not willing for surgery on the other normal eye.16,17 Lid lag on down gaze following sling surgery were informed to all the patients.

Levator disinsertion followed by frontalis sling was performed in 13 patients with Marcus Gunn jaw winking phenomenon. Out of that, 6 were male and 7 were female. In 11 patients of Blepharophimosis syndrome, 2 stages of surgeries were carried out. First stage, epicanthal fold and telecanthus were corrected with mustard's double Z plasty followed by second stage of correction of ptosis with mild under-correction of frontalis sling (7.5\%).18,16 Crutch glasses were given for 2 patients with CPEO and frontalis sling was not done due to absence of Bell's phenomenon.

Under-correction formed the major complication reported in this study. It was noticed in 11 patients $(7.5 \%)$. This was purposefully done due to superior rectus palsy to avoid exposure keratitis. Six patients reported with due to slipping of knot, for which re-surgery was done after 3-6 months.

In conclusion, the incidence of ptosis was found to be more common in the age group of, one year to 20 years. This shows the cosmetic consciousness in this age group. Among the congenital ptosis, simple congenital ptosis formed the major group. Superior rectus weakness, Blepharophimosis syndrome and Marcus Gunn jaw winking phenomenon were the major ocular anomalies associations. Mental retardation and congenital heart disease formed the major systemic association with rare association of CODAS syndrome and Noonan's syndrome.

Three different surgical procedures were followed in most of the cases. Among this frontalis sling surgery formed the major group. As ptosis leads to unacceptable cosmetic appearance, defective vision and superior visual field, the fight against ptosis by surgical procedures were successful. Surgeries restored a stable, normal functioning eyelid and improves superior visual field, thereby form the main treatment of choice.

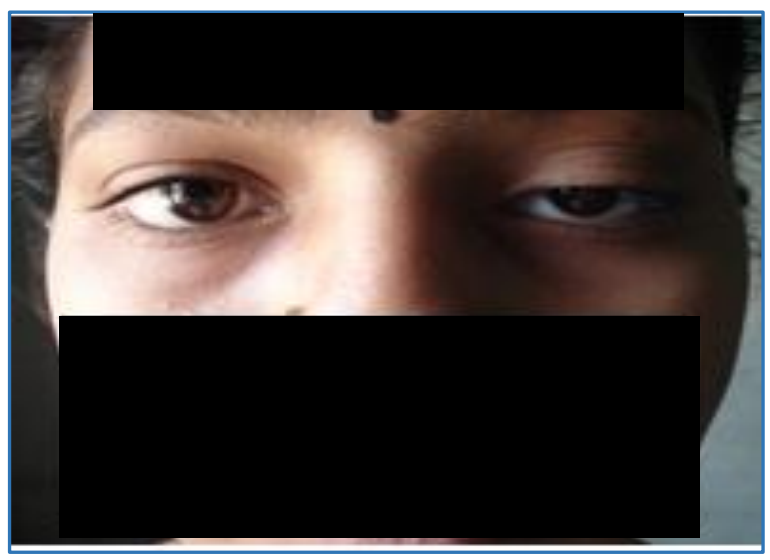

Pic. 1: Left Eye Simple Moderate Congenital Ptosis

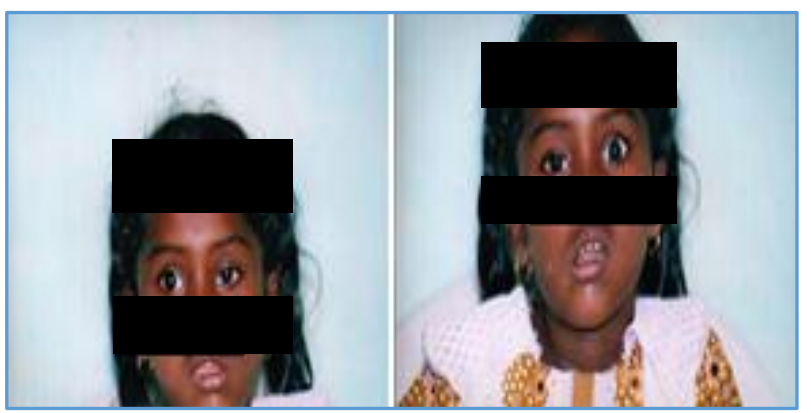

Pic. 2: Marcus Gunn Jaw-Winking Phenomenon- Left

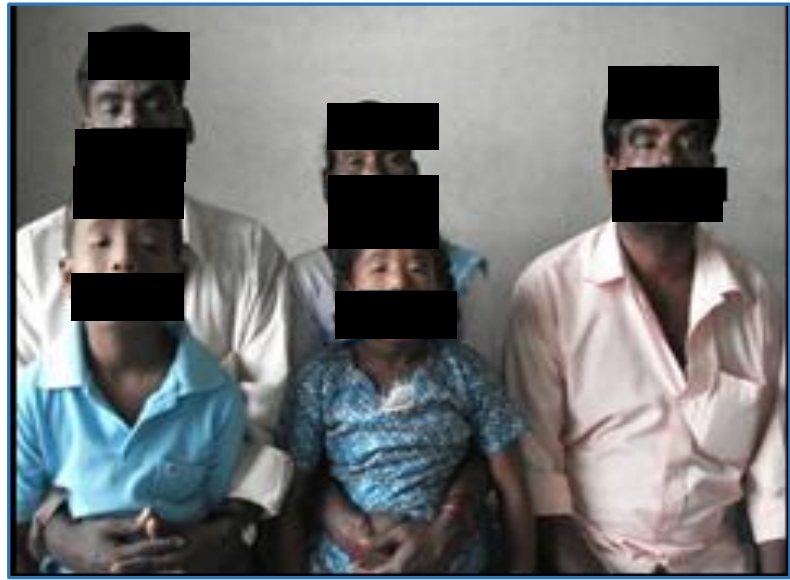

Pic. 3: Blepharophimosis Syndrome Family

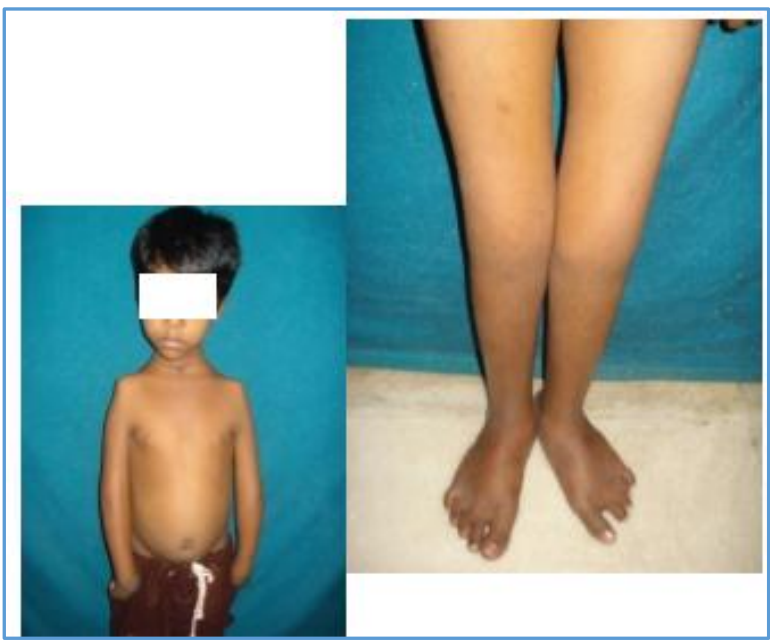

Pic. 4: Systemic Association-Arthrogryposis Multiplexa

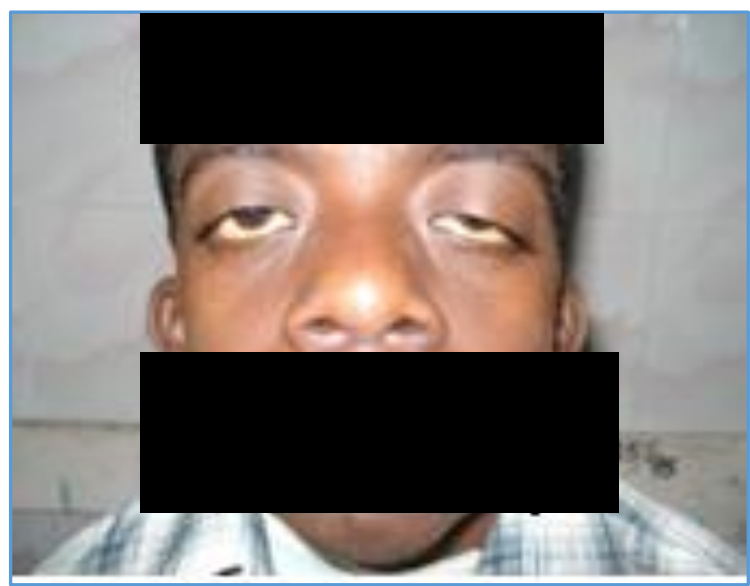

Pic. 5: Noonan's Syndrome with Left Eye Ptosis 


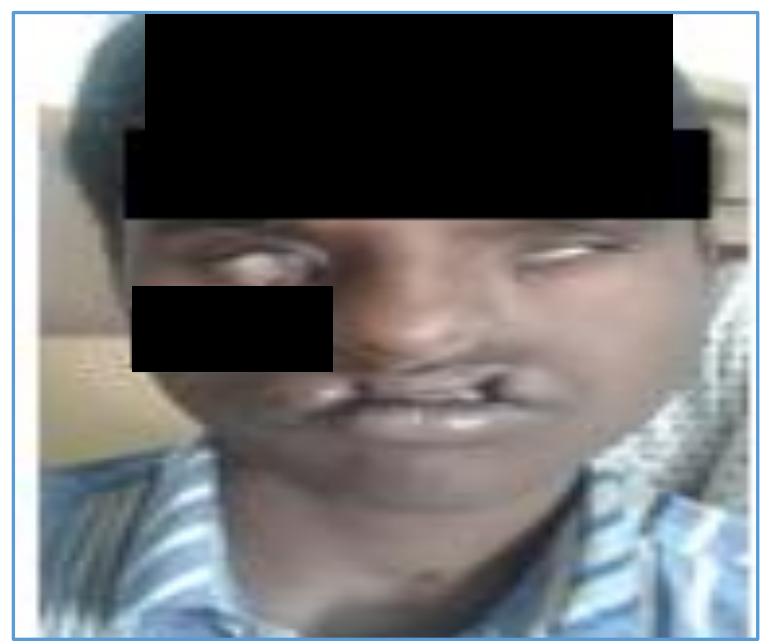

Pic. 6: Associated Congenital Cleft Palate and Cleft Lip

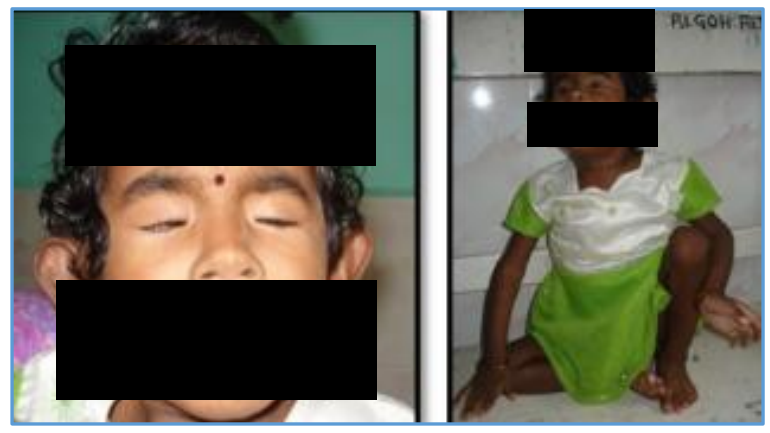

Pic. 7: Cerebro-oculo-dento-auricular Syndrome

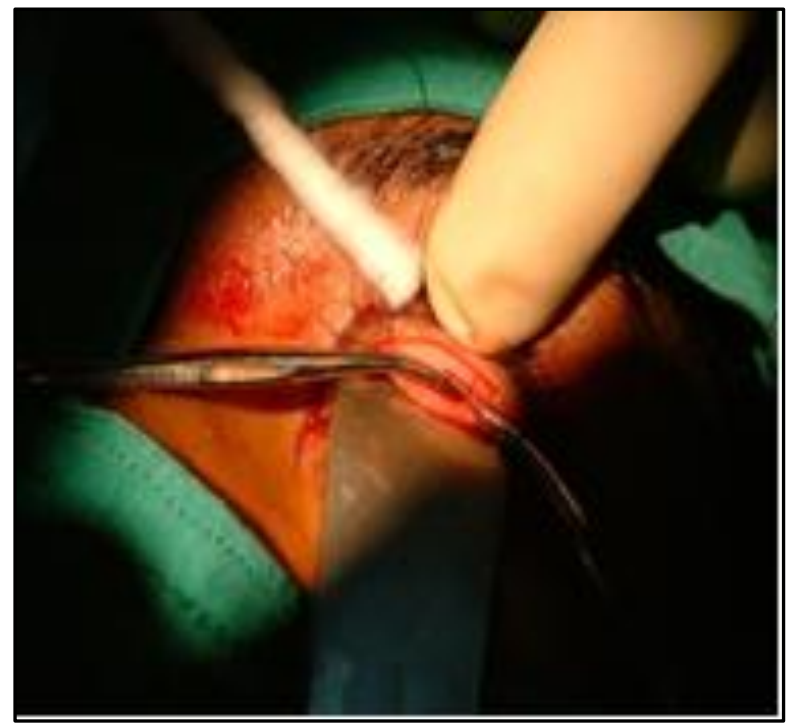

Pic. 8: Left Side Fasanella-Servat

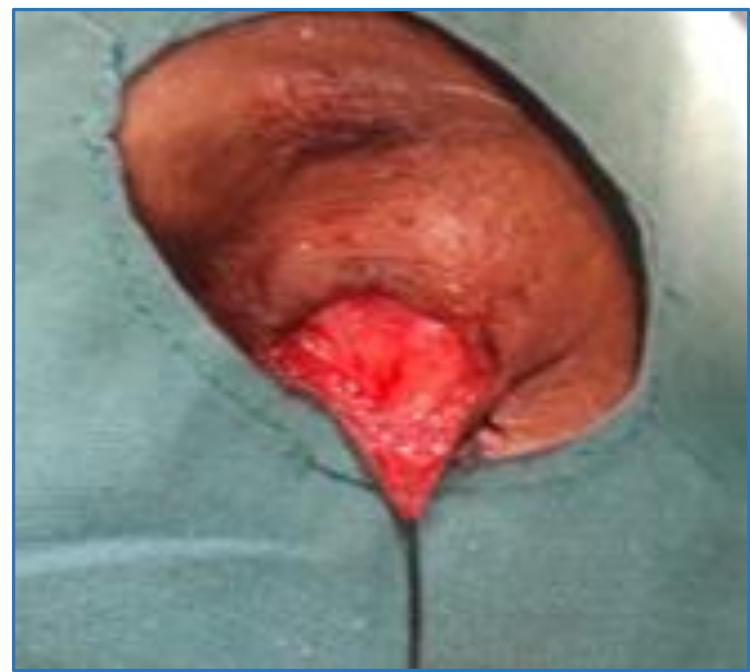

Pic. 9: Levator Resection

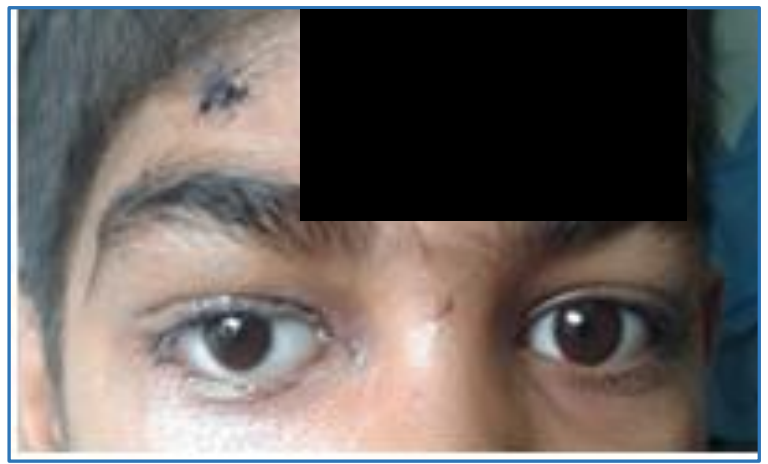

Pic. 10: Frontalis Sling-Post OP

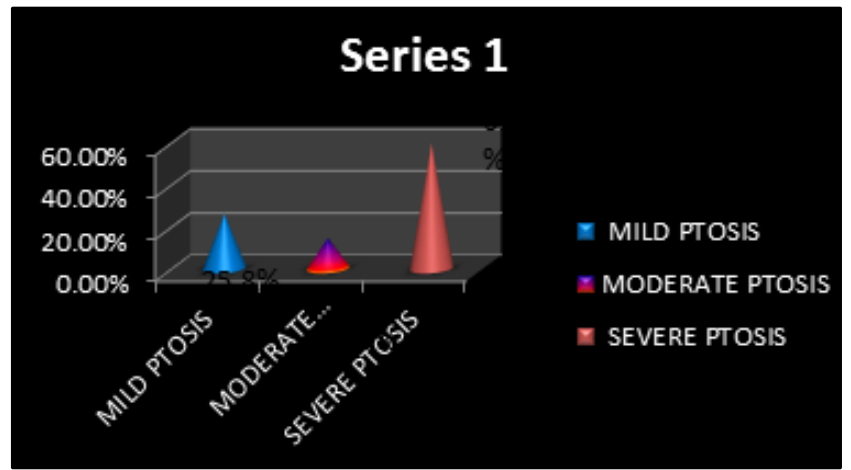

Chart 1: Degree of Congenital Ptosis

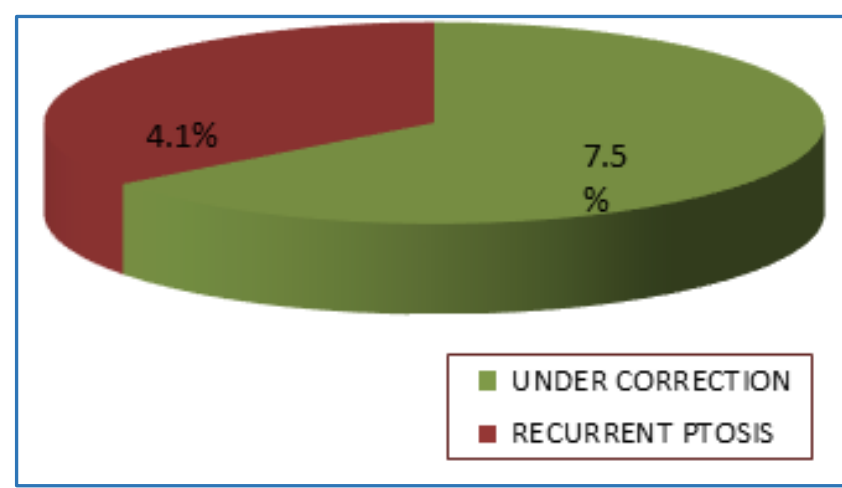

Chart 2: Complications Following Ptosis Surgery 


\begin{tabular}{|c|c|c|c|}
\hline $\begin{array}{c}\text { SL. } \\
\text { NO. }\end{array}$ & $\begin{array}{c}\text { OCULAR } \\
\text { ASSOCIATIONS }\end{array}$ & NO. OF CASES & PERCENTAGE \\
\hline 1 & SIMPLE PTOSIS & 77 & $52.7 \%$ \\
\hline 2 & SUPERIOR RECTUS PALSY & 30 & $20.5 \%$ \\
\hline 3 & MARCUS GUNN JAW-WINKING PHENOMENON & 13 & $8.9 \%$ \\
\hline 4 & BLEPHAROPHIMOSIS SYNDROME & 11 & $7.5 \%$ \\
\hline 5 & STRABISMUS & 6 & $4.1 \%$ \\
\hline 6 & CONGENITAL NYSTAGMUS & 3 & $2.1 \%$ \\
\hline 7 & LID COLOBOMA & 2 & $1.4 \%$ \\
\hline 8 & CPEO & 2 & $1.4 \%$ \\
\hline 9 & DUANES RETRACTION SYNDROME TYPEI & 2 & $1.4 \%$ \\
\hline \multicolumn{2}{|r|}{ Table 1: Ocular Associations of Congenital Ptosis } \\
\hline
\end{tabular}

\begin{tabular}{|c|c|c|c|c|c|c|}
\hline SL. NO. & SURGERIES & $\begin{array}{c}\mathbf{1 - 1 0} \\
\text { YEARS }\end{array}$ & $\begin{array}{c}\mathbf{1 1 - 2 0} \\
\text { YEARS }\end{array}$ & $\begin{array}{c}\mathbf{2 1 - 3 0} \\
\text { YEARS }\end{array}$ & TOTAL & PERCENTAGE \\
\hline 1 & FRONTALIS SLING & 28 & 32 & 10 & 70 & $56.5 \%$ \\
\hline 2 & LEVATOR RESECTION & 3 & 14 & 4 & 21 & $16.9 \%$ \\
\hline 3 & FASANELLA SERVAT & 2 & 1 & -- & 3 & $2.4 \%$ \\
\hline 4 & $\begin{array}{c}\text { LEVATOR DISINSERTION } \\
\text { FOLLOWED BY SLING }\end{array}$ & 3 & 8 & 2 & 13 & $10.5 \%$ \\
\hline 5 & $\begin{array}{c}\text { DOUBLE Z PLASTY WITH } \\
\text { SLING }\end{array}$ & 5 & 4 & 2 & 11 & $8.9 \%$ \\
\hline 6 & $\begin{array}{c}\text { SQUINT SURGERY } \\
\text { FOLLOWED BY SLING }\end{array}$ & 2 & 4 & -- & 6 & $4.8 \%$ \\
\hline \multicolumn{7}{|c|}{ Table 2: Surgeries Done in Congenital Ptosis } \\
\hline
\end{tabular}

\section{REFERENCES}

1. Myon Yanoff, Jay S Duker, James J Augsborger Blepharoptosis, 1999, London, chap-7, pg-5.1-5.3.

2. Leonard B Nelson. Book of Pediatric ophthalmology, 1998, Philadelphia, pg-357-359.

3. Peymen, Sanders and Golberg- principles and practice of ophthalmology, first edition, 1987, vol-III.

4. Mark R Levine- Manual of oculoplastic surgery, 1988, Churchill, pg-100.

5. Iliff WJ, Iliff CE -Oculoplasty surgery, WB Saunders, 1979, 28 Sidney A Fox- Surgery of ptosis, 1980, Williams and Wiskins, 206. New York. George L Spaeth, ophthalmic surgery, 2003, Philadelphia.

6. Geoffrey J Gladstone, Evan H Black, Shoibmynt. Oculoplastic surgery atlas of eyelid disorders, 2002, New York, pg-57 \& 59.

7. Collin JRO- A manual of systemic eyelid surgery, second edition, 1989, Churchill Livingstone.

8. Duke Elder's- System of ophthalmology, vol-XIII, part-I, St Louis, CV Mosby 1974, 557.
9. Steel DH. Visual affect in ptosis. American Journal of Ophthalmology, 1996, oct, 122(4), pg-550-6.

10. Daniel M Albert, Frederic A Jakobie, Jesse SigelmanAdvanced technique in ocular surgery, 2000, Philadelphia, pg-3336.

11. Wales, Ogata -Blepharophimosis-ptosis-epicanthus inversus syndrome, Horm res, July, 1998, 14(4), pg-271-6.

12. Harold Chen. Arthrogryposis-neolaki.net, Morgent, MMC govern emedicine, Medscape 18 agustos, 23-24, 2015.

13. Bhatacherjee H. Syndrome with oculo-dento-auriculocerebral malformation, IJO, vol 32, 185-186, 1984.

14. Tyers AG, Collins JRO. Colour atlas of ophthalmic plastic surgery, 1995, Hong Kong. 159, 128.

15. Crowell Beard- Ptosis, third edition, 1987, CV Mosby, pg55-56.

16. Byron Smith, Thomas D Chrubini. Oculoplastic surgery, 1970, New York, 125.

Roper Hall MJ - Stallard's eye surgery, seventh edition, 1989, vergeshe publishing house, pg-145. 